\title{
PEMBUATAN ALAT PENDETEKSI KESALAHAN PADA PEMASANGAN TERMINAL BATERAI KENDARAAN
}

\author{
Saparudin, Sukma Firdaus, Marlia Adriana \\ Jurusan Mesin Otomotif Politeknik Negeri Tanah Laut \\ Email : Syafar.dea@gmail.com
}

\begin{abstract}
ABSTRAK
Dunia otomotif berkembang sangat cepat, contohnya pada sistem pengapian kendaraan, mulai dari penggunaan platina, Capacitive Discharge Ignition (CDI), dan sekarang Electronic Control Unit (ECU) yang memerlukan sistem kelistrikan. Sumber listrik utama pada kendaraan adalah baterai yang menyuplai arus searah. Hasil putaran mesin di ubah oleh dinamo isi menjadi energi listrik, salah satu fungsinya untuk mengaktifkan material pada komponen baterai yang tidak bisa terus menerus aktif menyuplai daya listrik. Maka dari itu perawatan pada aki harus dilakukan secara berkala, mulai dari mengecek kondisi baterai sampai mengganti dengan baterai yang baru. Pada saat pergantian baterai, terminal baterai dilepas dan dipasang kembali. Dalam hal ini, terdeteksi terjadinya kesalahan pada saat pemasangan terminal baterai, baik karena kelalaian, terburu-buru dan hal lain yang memacu serta produksi kendaraan hanya memberikan indikasi kutub baterai dengan tanda dan warna, yang tidak bisa menjamin hal tersebut. Dampak yang ditimbulkan adalah kendaraan tidak dapat dihidupkan. Current Protector adalah sebuah alat yang dapat mendeteksi, mengamankan dan memberitahukan apabila terjadi kesalahan pada saat pemasangan terminal baterai. Alat ini tersusun oleh komponen-komponen elektronik dioda, relay, resistor, light emitting diode (LED), Buzzer dan sekering. Sehingga, meskipun pemasangan terminal aki tertukar, kendaraan masih dapat dihidupkan.
\end{abstract}

Kata kunci: Perawatan baterai, alat pendeteksi kesalahan pada pemasangan terminal baterai kendaraan.

\section{PENDAHULUAN}

Kendaraan merupakan transportasi darat yang digerakkan dengan tenaga mesin, biasanya menggunakan bahan bakar minyak terutama bensin dan solar yang didukung oleh sistem elektronik luar seperti lampu besar atau kepala, lampu tail/belakang, lampu rem, lampu jarak atau kota, lampu tanda belok, Lampu hazard, lampu plat nomor, lampu mundur, lampu kabut, klakson dan sistem elektronik dalam seperti lampu indicator dan instrument lainya yang terpasang pada dashboard, lampu ruangan atau lampu kabin. Serta pada waktu starter kendaraan semua itu memerlukan suplai listrik yang berasal dari Baterai kendaraan sebagai penyedia dan dinamo Ampere (Alternator) sebagai charge Baterai pada kendaraan.

Pada saat pergantian Baterai kendaraan, terdeteksi kesalahan pemasangan terminal, karena dari pabrik hanya memberikan indikasi kutub Baterai dengan tanda, yaitu kutub Baterai positif (+) dengan tanda kabel bewarna merah dan kutub Baterai negatif (-) dengan tanda kabel bewarna hitam yang masih saja terjadi kesalahan pemasangan dari berbagai kasus dilapangan, yang mengakibatkan kendaraan tidak dapat beroperasi. Contohnya pada mobil Kijang Innova V 2.0 akan membuat beberapa sekering terputus, diantaranya sekering ECU putus yang menyebabkan mesin tidak bisa hidup dan ECU mengalami gangguan atau rusak, sekering Electronic Throttle Control System - Intelligent (ETCS-I) putus yang menyebabkan bensin tidak bisa digas dan Rotary Per Minute (RPM) kendaraan tidak mau naik dan sekering Alternator (ALT).

Dengan begitu fatalnya dari kesalahan pemasangan terminal Baterai kendaraan, indikasi yang hanya memberikan tanda pada terminal Baterai, tidak bisa dijadikan jaminan untuk keamanan pada sistem elektronik kendaraan dan antisipasi pada saat terjadi kesalahan pemasangan. Maka harus ada sebuah alat yang dapat mengamankan sistem elektronik kendaraan dan memberi tanda apabila terjadi kasus kesalahan pada waktu pemasangan terminal Baterai pada kendaraan.

Penelitian ini bertujuan untuk mengetahui cara pembuatan dan cara kerja alat pendeteksi pada pemasangan Baterai kendaraan untuk dapat mengamankan sistem kelisrikan pada kendaraan dan memberitahukan kepada pemilik kendaraan ketika terjadinya kesalahan pada saat pemasangan terminal Baterai.

\section{METODOLOGI}

\section{Pembuatan Alat Pendeteksi}

Dalam penelitian ini, pembuatan alat pendeteksi kesalahan pada pemasangan Baterai kendaraan menggunakan metode Current Protektor (CP). Prosedur yang dilakukan untuk membuat alat ini, dimulai dengan 
mempersiapkan papan Printed Circuit Board (PCB) yang digunakan untuk meletakkan komponen-komponen elektronik. Komponen yang diletakkan pada papan PCB adalah Dioda, Relay, Resistor, Light Emitting Diode incremental $3 \mathrm{~mm}$ keatassampai di (LED), dan Fuse secara berurutan. Dioda memiliki empat kaki, dua kaki digunakan untuk menghubungkan terminal Baterai dan dua kaki lagi digunakan untuk terminal output Baterai, yang dihubungkan dengan dua Relay, Resistor dan LED dalam rangkaian paralel. Untuk menghubungkan semua komponen-komponen tersebut menggunakan kabel, kawat timah, dan solder. Setelah perakitan komponen-komponen elektronik selesai, dilakukan uji coba pada kendaraan. Kemudian pengambilan hasil uji coba meliputi fungsi alat (mendeteksi kesalahan dalam pemasangan terminal Baterai, mengamankan sistem kelisrikan pada kendaraan, memberitahukan terjadinya kesalahan pada saat pemasangan terminal Baterai) dan daya yang dibutuhkan, sehingga akhirnya diperoleh alat Current Protektor (CP) yang mendeteksi dan mengamankan output kelistrikan pada kendaraan meskipun terminal Baterai kendaraan tertukar. G

\section{Proses Sistem Pengaman}

Proses sistem pengaman pada Gambar 1 pembuatan alat pendeteksi pada pemasangan Baterai kendaraan, dimulai pada pengkonversian dari energi mekanis ke energi listrik adalah putaran engine dengan Alternator. Alternator disebut juga dinamo isi (distributor) menghasilkan arus listrik Alternating Current (AC) dan di ubah menjadi arus listrik Direct Current (DC) untuk sistem elektikal kendaraan dan pengisian Baterai. Baterai Baterai kendaraan dipasang sebagai penyimpanan sumber energi listrik pada kendaraan. Yang pertama komponen diode yang akan mengubah kutub Baterai positif (+) dengan hasil keluaran kutub negatif (-), dan mengubah kutub Baterai negatif (-) dengan hasil keluaran kutub positif $(+)$, relay akan mendapat arus sehingga menimbulkan magnet dan mengerakkan saklar relay dan Light Emetting Diode warna merah akan hidup. Apabila tidak terjadi kesalahan pada waktu pemasangan terminal Baterai maka Relay tidak bergerak dan tidak mengeluarkan suaran dan Light Emetting Diode warna hijau akan hidup. Setelah rangkaian pengaman terminal pada Baterai kendaraan kemudian di alirkan ke sistem elektronik bagian luar, seperti lampu besar atau kepala, lampu tail/belakang, lampu rem. Dan sistem elektronik bagian dalam, seperti lampu ruangan atau lampu kabin. Terakhir Baterai kendaraan digunakan untuk memutar engine dengan mengunakan dinamo starter pada saat starting dan terulang kembali dikonversikan dari energi mekanis ke energi listrik dengan Alternator pada saat mesin hidup.

Gambar 1 Proses Sistem Pengaman pada Output Baterai Kendaraan

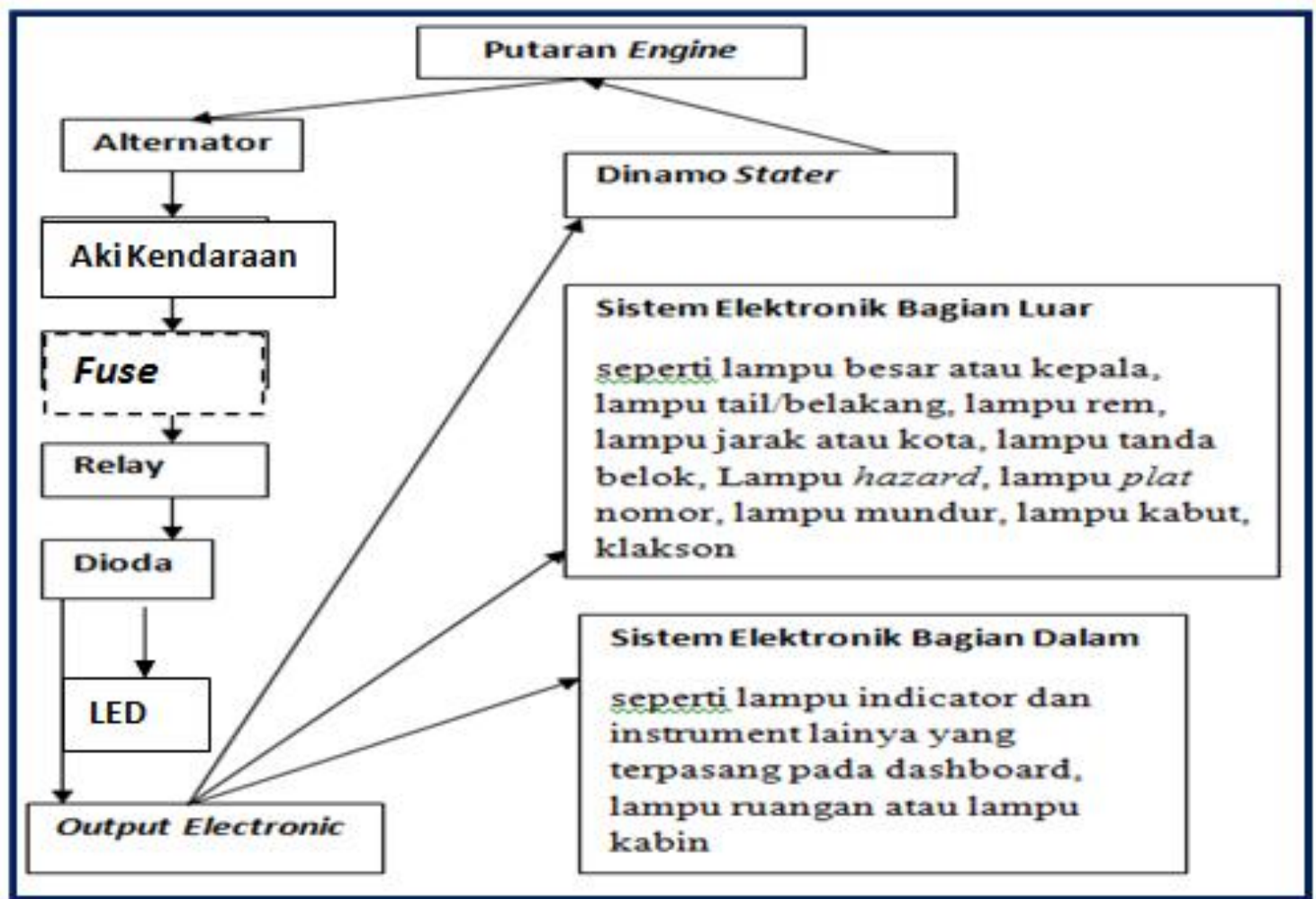




\section{Tahapan Perakitan Alat Current Protektror (CP)}

Dalam perakitan alat CP pada Gambar 2 antara lain dimulai dari menyiapkan Printed Circuit Board (PCB) dan solder. Kemudian pasang jembatas Dioda 50 Ampere yang mempunyai empat kaki mengunakan obeng plus untuk membuat lobang pada papan PCB. Pasang Dua Relay 12 Volt-25 Ampere, satu Relay dihubungkan melalui input kutub negatif dengan kutub negatif output dan satu Relay lagi dihubungkan melalui input kutub positif dengan kutub positif output yang dirangkai dengan rangkaian paralel pada kaki-kaki dioda. Pasang dua Dioda 5 Ampere yang terhubung secara paralel ke Relay dengan dioda, kemudian pasang dua Resistor 1,5 $\mathrm{K} \Omega$ dengan paralel yang dihubungkan ke input Baterai untuk menyakan Light Emitting Diode (LED). Pasang Fuse 20A pada terminal positif ke Baterai yang dihubungkan ke inputa kaki dioda positif . Pasang Buzzer 12 Volt pada kutub positif terminal Baterai dan kutub positif pada terminal output Baterai dengan rangkaian seri.

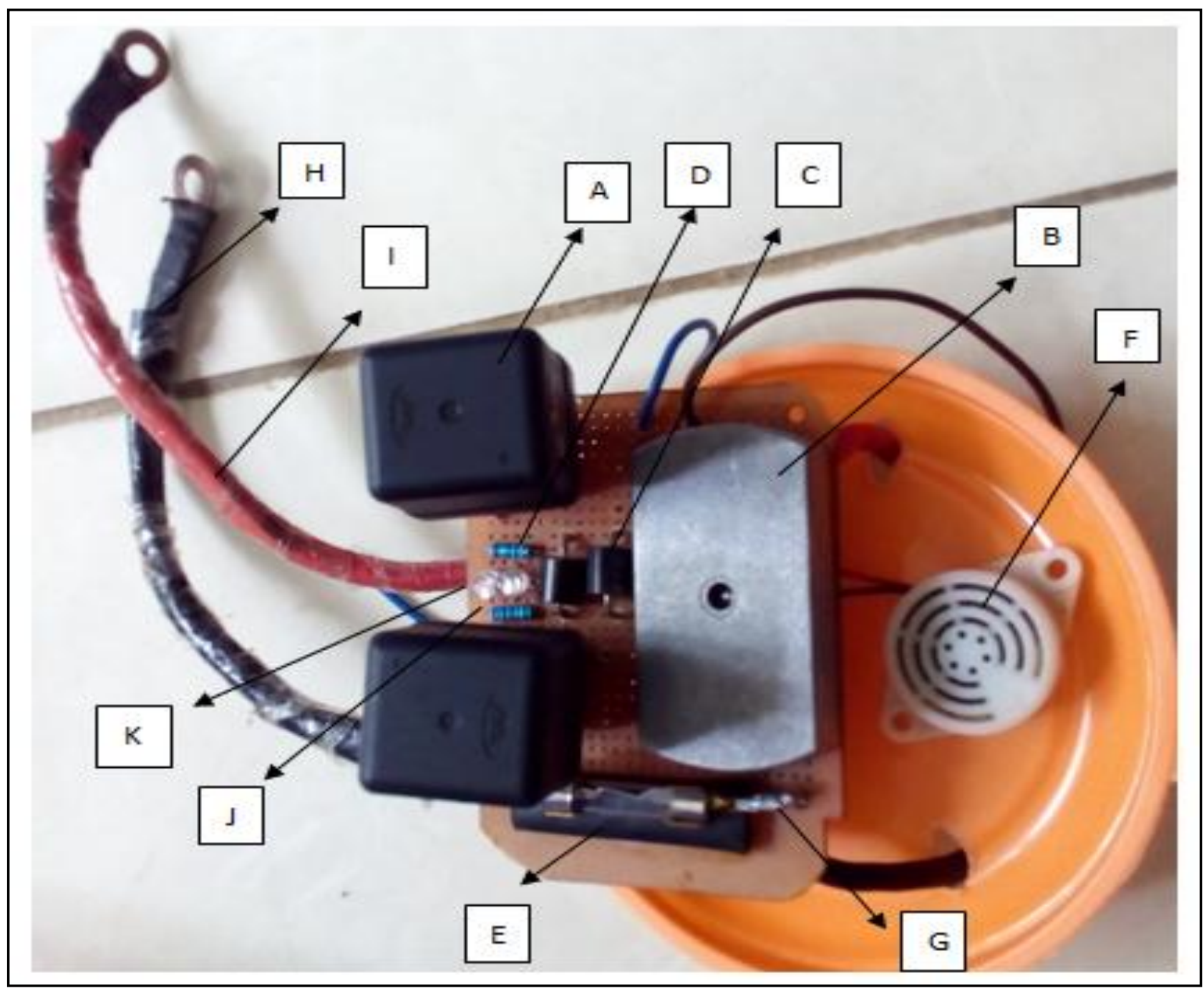

Gambar 2 Alat Current Protector

Keterangan:

$\begin{array}{ll}\text { A. } & \text { Relay } 12 \text { Volt-25A } \\ \text { B. } & \text { Jembatan Dioda 50A } \\ \text { C. } & \text { Dioda } 5 \text { Ampere } \\ \text { D. } & \text { Resistor } 1,5 \mathrm{~K} \Omega \\ \text { E. } & \text { Fuse } 20 \text { Ampere } \\ \text { F. } & \text { Buzzer } 12 \text { Volt }-6 \mathrm{~A} \\ \text { G. } & \text { Kabel tunggal } \\ \text { H. } & \text { Kabel serabut warna hitam } \\ \text { I. } & \text { Kabel serabut warna merah } \\ \text { J. } & \text { LED warna merah } 1,7 \mathrm{~V}-30 \mathrm{~mA} .\end{array}$

K. LED warna Hijau 2,2 Volt-25 mA.

\section{HASIL DAN PEMBAHASAN}

\section{Cara Kerja Alat Current Protector (CP)}

Dalam cara kerja alat CP pada Gambar 3 memiliki beberapa singkatan dalam penyebutan komponen elektronik seperti: Baterai (BAT1), Resistor Pertama dan Resistor Kedua (R1-R2), Jembatan Dioda (D1- 
D2-D3-D4), Dioda kecil (D5-D6), LED warna Merah

(D7), LED warna Hijau (D8), Buzzer (BUZ1).

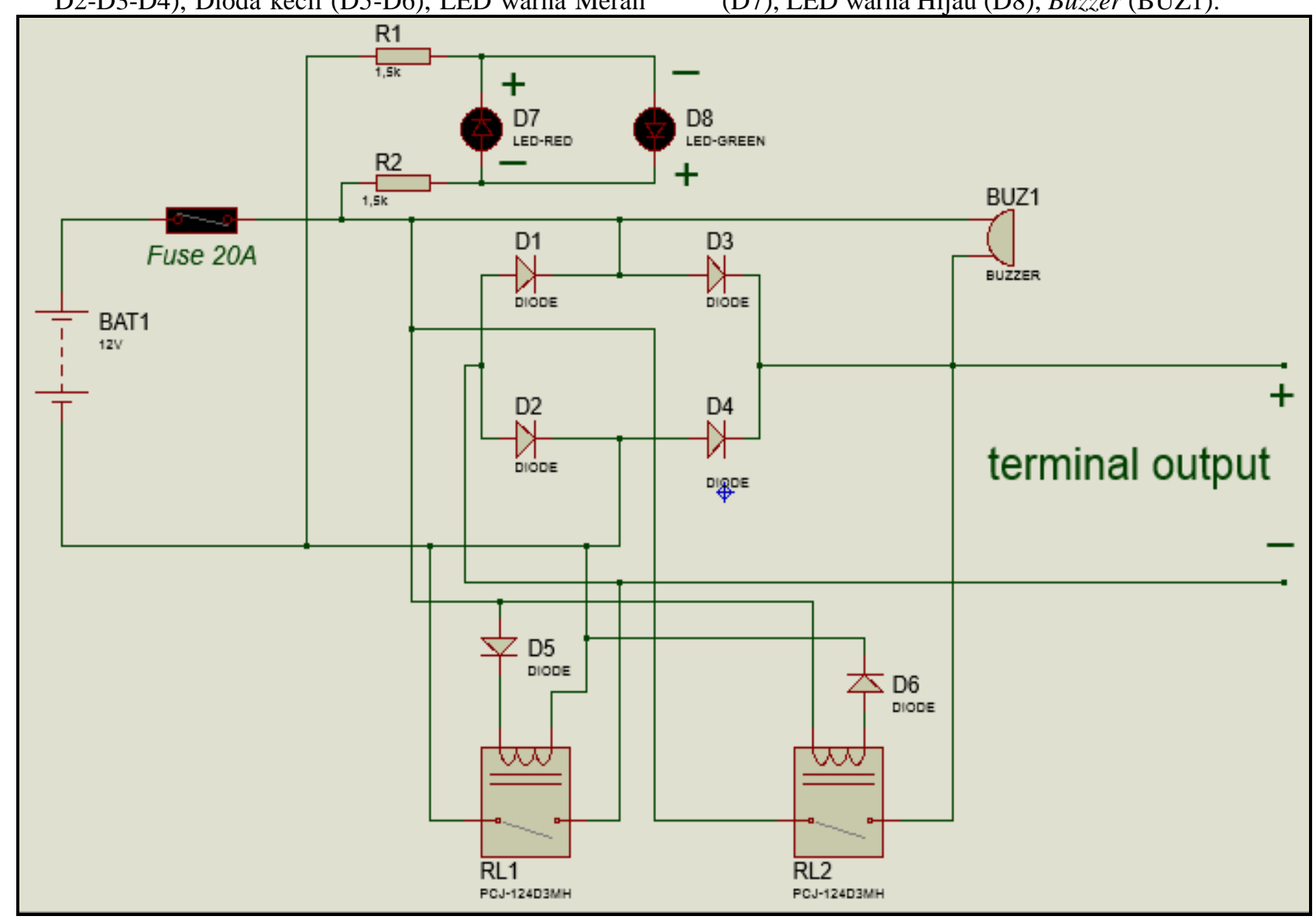

\section{Gambar 3 Schematic Wiring Diagram}

Ketika Pemasangan Terminal Baterai pada Tabel 1 Benar, arus lisrik mengalir dari kutub positif BAT1 menuju ke salah satu kaki jembatan dioda menuju D3, kemudian langsung menuju ke terminal output positif, dan arus lisrik mengalir dari kutub negatif BAT1 menuju ke salah satu kaki jembatan dioda menuju D2, kemudian langsung menuju ke terminal output negatif. Arus lisrik mengalir dari kutub positif BAT1 menuju ke resistor menuju ke kaki negatif LED warna merah dan ke kaki positif LED warna hijau, selanjutnya arus lisrik mengalir dari kutub negatif BAT1 menuju ke resistor menuju ke kaki positif LED warna merah dan ke kaki negatif LED warna hijau, maka ketika termianal baterai benar LED warna hijau menyala. Arus lisrik mengalir dari kutub positif BAT1 menuju kesalah satu kaki R2 dan ke D5 (arus yang masuk hanya arus positif) kemudian ke salah satu kaki RL1, arus lisrik mengalir dari kutub negatif BAT1 menuju ke R1 dan ke D6 (arus yang masuk hanya arus negatif) kemudian ke salah satu kaki R2, sehingga ketika pemasangan terminal baterai benar, maka kedua relay di aliri listrik dan mengasilkan magnet untuk menggerakan saklar pada relay dengan sistem charge, karena saklar R1 terhubung dengan terminal negatif baterai dan terminal output negatif, serta saklar R2 terhubung dengan terminal positif baterai dan terminal output positif.
Ketika Pemasangan Terminal Baterai Tertukar, arus lisrik mengalir dari kutub positif BAT1 menuju ke salah satu kaki jembatan dioda menuju D1, kemudian langsung menuju ke terminal output positif, dan arus lisrik mengalir dari kutub negatif BAT1 menuju ke salah satu kaki jembatan dioda menuju D4, kemudian langsung menuju ke terminal output negatif. Arus lisrik mengalir dari kutub positif BAT1 menuju ke resistor menuju ke kaki positif LED warna merah dan ke kaki negatif LED warna hijau, selanjutnya arus lisrik mengalir dari kutub negatif BAT1 menuju ke resistor menuju ke kaki negatif LED warna merah dan ke kaki positif LED warna hijau, maka ketika termianal baterai tertukar LED warna merah menyala. Arus lisrik mengalir dari kutub negatif BAT1 menuju kesalah satu kaki R2 dan ke D5 (arus yang masuk hanya arus positif) sehingga arus tidak dapat masuk ke salah satu kaki RL1, arus lisrik mengalir dari kutub positif BAT1 menuju ke R1 dan ke D6 (arus yang masuk hanya arus negatif) sehingga arus tidak dapat masuk ke salah satu kaki R2, sehingga ketika pemasangan terminal baterai tertukar, maka kedua relay di tidak aliri listrik sehingga tidak mengasilkan magnet untuk menggerakan saklar R1 dan R2, dan menjadi sistem discharge karena saklar R1 tidak terhubung dengan terminal negatif baterai dan terminal output negatif, serta saklar R2 tidak terhubung dengan terminal positif baterai dan terminal 
output positif. Arus lisrik mengalir dari kutub negatif BAT1 menuju ke salah satu kaki BUZ1, dan kaki BUZ1 lagi ke terminal output positif, sehingga ketika pemasangan terminal baterai tertukar, buzzer akan berbunyi.

Tabel 1 Sistem Kerja Current Protector

\begin{tabular}{|c|c|c|c|c|c|c|}
\hline \multicolumn{7}{|c|}{ SISTEM KERJA CURRENT PROTECTOR } \\
\hline No & $\begin{array}{c}\text { Pemasangan } \\
\text { Terminal } \\
\text { Baterai }\end{array}$ & $\begin{array}{c}\text { Jembatan } \\
\text { Dioda }\end{array}$ & Relay & LED & Buzzer & Sistem Rangkaian \\
\hline 1 & BENAR & ON & ON & $\begin{array}{c}\text { Warna hijau } \\
\text { menyala }\end{array}$ & OFF & CHARGE \\
\hline 2 & TERTUKAR & ON & OFF & $\begin{array}{c}\text { Warna } \\
\text { Merah } \\
\text { menyala }\end{array}$ & ON & DISCHARGE \\
\hline
\end{tabular}

Power (Daya) Listrik Yang Dibutuhkan Alat Current Protector (CP)

Daya yang dibutuhkan alat CP pada Tabel 2 untuk mengdeteksi menggunakan LED pada saat pemasangan terminal baterai benar sebesar 0,55 Watt. Mengdeteksi menggunakan LED pada saat pemasangan terminal baterai tertukar sebesar 0,51 Watt. Memberitahukan pemasangan terminal baterai tertukar menggunakan Buzzer sebesar 72 Watt. Akan tetapi dalam mengamankan sistem kelistrikan pada mobil tidak membutuhkan daya listrik, karena menggunakan komponen elektronik dioda yang berfungsi mengarahkan arus tanpa membutuhkan daya untuk fungsi tersebut.

Tabel 2 Total Kebutuhan Daya

\begin{tabular}{|c|c|c|c|c|c|}
\hline No & $\begin{array}{c}\text { Terminal } \\
\text { Baterai }\end{array}$ & $\begin{array}{c}\text { Daya pada } \\
\text { LED Hijau }\end{array}$ & $\begin{array}{c}\text { Daya pada } \\
\text { LED Merah }\end{array}$ & $\begin{array}{c}\text { Daya Pada } \\
\text { Buzzer }\end{array}$ & Total Daya \\
\hline 1 & Benar & 0,55 Watt & - & - & 0,55 Watt \\
\hline 2 & Tertukar & - & 0,51 Watt & 72 Watt & 72,51 Watt \\
\hline
\end{tabular}

\section{Penerapan Alat CP Pada Kendaraan Dan Kendaraan \\ Dari hasil uji coba penerapannya pada kedaraan V-} IXION 150cc ternyata mampu mendeteksi kesalahan pada pemasangan Baterai yang membutuhkan arus dibawah 20A dalam sistem kelistrikannya. Dilihat dari kebutuhan daya yang paling besar pada motor starter yang membutuhkan arus listrik sebesar 10,5 Ampere . alat ini dipasang setelah terminal Baterai diletakkan sesuai kondisi ruang dan kemudian ke output dengan rangkaian terminal Baterai harus menggunakan rangkaian semiparalel, input dari alternator dan output Baterai.

\section{KESIMPULAN}

Telah berhasil membuat alat pendeteksi kesalahan pada pemangan terminal baterai kendaraan dengan tiga cara kerja yaitu mendeteksi, mengamankan dan memberitahukan kepada pemilik apabila terjadi kesalahan pemasangan terminal baterai. Dengan demikian alat pendeteksi ini dapat digunakan sebagai pengama arus (Current Protector) pada kendaraan ringan yang hanya membutuhka daya maksimal 20 Ampere (A).

\section{DAFTAR PUSTAKA}

[1] Agus KP. 2012. Prototipe Sistem Keamanan Terkoneksi Dengan Pos Keamaman Menggunakan Sensor PIR Dan HP Siemens C45 Berbasis Atmega 16. Yogyakarta : Penerbit Universitas Negeri Yogyakarta.

[2] Daryanto. 2010. Teknik Mekatronika Cetak I. Bandung : Penerbit Satu Nusa.

[3] Listiono FA, 2012. Identifikasi, Overhoule, dan Pengujian Sistem Pengisian Mesin L15A Honda Jazz VTEC. Semarang. Penerbit Universitas negeri Semarang.

[4] Manurung Panuel. 2015. Analisa Daya pada Baterai dengan Metode Charge dan Dischaege. Medan : Penerbit Universitas Sumatera Utara.

[5] Khusnussairi. 2013. Pengujian Sistem Pengisian pada Mesin Honda Jazz Tipe L13A. Semarang : Penerbit Universitas Negeri Semarang.

[6] Nuh Muhammad, DEA, Prof, DR. 2013. Teknik Dasar Elektronika Komunikasi. Jakarta : Penerbit Kementerian Pendidikan dan Kebudayaan RI.

[7] Nurmawan Aji. 2015. Pengertian dan Prinsip Kerja Sekering (Fuse, Patron Lebur). Aceh.

[8] Oklilas AF. 2016. Elektronika Dasar. Palembang : Penrbit Universitas Sriwijaya.

[9] Wicaksono Handy. 2008. Prinsip dan Aplikasi Relay.kota : Penerbit Universitas Kristen Petra. 